\title{
Interleukin-1ß Attenuates Excitatory Amino Acid-Induced Neurodegeneration in vitro: Involvement of Nerve Growth Factor
}

\author{
Paul J. L. M. Strijbos and Nancy J. Rothwell \\ Neuroscience Division, School of Biological Sciences, University of Manchester, M13 9PT United Kingdom
}

\begin{abstract}
Certain cytokines have been reported to exert neurotrophic actions in vivo and in vitro. In the present study, we investigated the possible neuroprotective actions of the cytokine

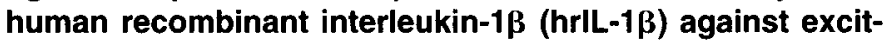
atory amino acid (EAA)-induced neurodegeneration in cultured primary cortical neurons. Brief (15 $\mathrm{min})$ exposure of cultures to submaximal concentrations of glutamate, NMDA, AMPA, or kainate caused extensive neuronal death ( $\sim 70 \%$ of all neurons). Neuronal damage induced by the EAAs was significantly reduced (up to $70 \%$ ) by pretreatment with $500 \mathrm{ng} / \mathrm{ml}\left(6.5 \times 10^{3} \mathrm{U} / \mathrm{ml}\right)$ hrlL-1 $\beta$ for $24 \mathrm{hr}$. The neuroprotective effect of hrlL-1 $\beta$ was reversed by coapplication of an IL-1 receptor antagonist (IL-1 ra, $50 \mu \mathrm{g} / \mathrm{ml}$ ). Neuroprotective actions of hrlL-1 $\beta$ were also reduced by administration of a neutralizing monoclonal antibody to NGF (65\% inhibition). In concordance, the neurotoxic actions of EAAs were significantly reduced (by $40 \%$ ) after pretreatment with NGF (100 ng/ml for $48 \mathrm{hr}$ ). Furthermore, an additive neuroprotective effect of approximately $75 \%$ was observed when cultures were exposed to a combination of hrIL-1 $\beta$ and NGF. In contrast, exposure of cultures to high concentrations hrlL-1 1 alone $\left(100 \mu \mathrm{g} / \mathrm{ml}, 1.3 \times 10^{6}\right.$ $\mathrm{U} / \mathrm{ml}$ ) for periods up to $72 \mathrm{hr}$ resulted in neurotoxicity, which was reversed by IL-1ra $(1 \mathrm{mg} / \mathrm{ml})$. These findings suggest that hrIL-1 $\beta$ can limit EAA-induced neuronal damage. These effects appear to be may be mediated, at least in part, via NGF. These findings may be relevant to the understanding of neurodegenerative diseases.
\end{abstract}

[Key words: interleukin-1, interleukin-1 receptor antagonist, NGF, cortical neurons, excitatory amino acids, in vitro, neurodegeneration]

Cytokines such as certain interleukins (ILs), granulocyte-macrophage colony-stimulating factor (GM-CSF), and tumor necrosis factor $\alpha(\mathrm{TNF} \alpha)$ have been implicated in the pathophysiology of several immune system-mediated CNS disorders including multiple sclerosis and bacterial meningitis, and various neurodegenerative disorders such as stroke and Alzheimer's disease

Received Oct. 25, 1994; accepted Nov. 10, 1994.

The authors wish to thank Ms. B. A. Wilde for excellent technical assistance and Dr. S. J. Hopkins and S. Brouwer for performing the DlON assay. We are grateful to Synergen (Colorado, USA) and Glaxo (Geneva, Switzerland) for the generous gifts of interleukin- 1 receptor antagonist and recombinant human interleukin- $1 \beta$ respectively. This work was supported by the Medical Research Council.

Correspondence should be addressed to Paul J. L. M. Strijbos, Neuroscience Research Group, Department of Molecular Pharmacology (Building 120), The Wellcome Research Laboratories, Langley Court, South Eden Park Road, Beckenham, Kent BR3 3BS, United Kingdom.

Copyright (C) 1995 Society for Neuroscience $0270-6474 / 95 / 153468-07 \$ 05.00 / 0$ (for review, see Patterson and Nawa, 1993; Rothwell and Relton, 1993). While constitutive expression of cytokines and their mRNAs is low in normal brain, local inflammation, brain tissue injury, convulsions, and cerebral ischemia all potently induce the synthesis and release of various cytokines in humans and experimental animals (Minami et al., 1991, 1993). Of these cytokines, IL-1 appears to play a particularly important role in the pathogenesis of CNS disorders (Rothwell and Relton, 1993). Administration of IL-1 into the brain of experimental animals elicits glial activation and proliferation, neuronal sprouting, scar formation, and neovascularization (Giulian and Lachman, 1985; Woodward et al., 1989), processes characteristic of brain trauma. Furthermore, increased concentrations of IL- 1 have been found in the brain or cerebrospinal fluid of patients suffering from various neurodegenerative disorders (Gallo et al., 1989; Griffin et al., 1989). Various lines of evidence have suggested that the cytokines induced by brain tissue injury may modify neuronal viability. For example, relatively low concentrations of IL-1, -4 , $-5,-7$, or -8 exert neurotrophic actions on hippocampal and cholinergic basal forebrain and septal neurons in culture when applied for short periods of time (Araujo, 1992; Araujo and Cotman 1993). However, when neuronal cultures are exposed to high concentrations of cytokines for extended periods of time, they can also exert neurotoxic actions reflected by reduced neuronal survival (Araujo, 1992). In vivo studies have demonstrated that central administration of a recombinant interleukin-1 receptor antagonist (IL-1ra) significantly inhibits neurodegeneration caused by focal ischemia or glutamatergic lesions in the rat (Relton and Rothwell, 1992).

It has been proposed that the neurotrophic actions of IL-1 are mediated via the induction of various neurotrophic factors including nerve growth factor (NGF) and fibroblast growth factor (FGF; Lindholm et al., 1987; Friedman et al., 1990; Yoshida and Gage, 1992). NGF is a particularly well characterized neurotrophic factor that is expressed at high levels in type 1 astrocytes, neurons and oligodendrocytes of the hippocampus, cerebral cortex, and olfactory bulb (Gonzalez et al., 1990; Carman-Krzan et al., 1991). Increased concentrations of NGF have been detected following several forms of brain trauma, and after administration of a variety of stimuli including IL-1, but also lipopolysaccharide, FGF, or TNF $\alpha$ (Friedman et al., 1990; Zafra et al., 1990; Vige et al., 1992). Exogenously administered NGF increases the survival and growth of basal forebrain cholinergic neurons that are deprived from their endogenous source of NGF by fimbriafornix axotomy (Williams et al., 1986; Kromer, 1987), and inhibits the neuronal death resulting from transient forebrain global ischemia (Shigeno et al., 1991). This is of particular interest since neuronal death may involve neuroexcitatory mechanisms 
due to excessive release of the excitatory amino acid (EAA) glutamate, which activates NMDA and non-NMDA receptors (Choi and Rothman, 1990). Indeed, NGF and FGF exert neuroprotective actions against excitotoxin-induced neurotoxicity in vivo and in vitro (Mattson et al., 1989; Schumacher et al., 1991; Frim et al., 1993; Shimohama et al., 1993), and both NMDA and non-NMDA receptor agonists induce NGF mRNA (Zafra et al., 1990; Ballarin et al., 1991). Agonists of the NMDA receptor also induce the synthesis of various other cytokines including IL-1 $\beta$ (Minami et al., 1991, 1993; A.-M. van Dam, P. J. L. M. Strijbos, N. J. Rothwell, and F. Berkenbosch, unpublished observations)

Thus, both IL- 1 and NGF appear to have important actions on neuronal survival and IL-1 released locally from activated astrocytes following CNS injury can stimulate the transcription of the NGF gene and the stabilization of NGF mRNA (Lindholm et al., 1987). Subsequent synthesis and release of NGF may provide trophic support to neurons and render them less sensitive to the neurotoxic actions of the EAAs. Neurotrophic actions of IL-1 may therefore depend directly on synthesis of NGF. We have tested this hypothesis using primary cortical neuronal cultures from neonatal rats by investigating the effects of exogenous hrIL-1 $\beta$ on EAA-induced neurodegeneration, and have assessed the involvement of NGF in the effects of hrIL-1 $\beta$.

Some of the data presented have been communicated previously in abstract form (Strijbos et al., 1993).

\section{Materials and Methods}

Cell culture. Dissociated cell cultures of fetal rat cerebral cortices were prepared from Sprague-Dawley rats (Charles River, UK) at day 18 of gestation. Cortices, without septal tissue, were dissected on ice in calcium/magnesium-free Hanks' balanced salt solution (GIBCO, Scotland) containing $100 \mathrm{IU} / \mathrm{ml}$ penicillin and $100 \mu \mathrm{g} / \mathrm{ml}$ streptomycin, and meninges and blood vessels removed. Cortical cells were dissociated by passage through fire-polished glass pipettes, seeded in 24-well Primaria (Falcon, UK) plates at a density of $5 \times 10^{5}$ trypan blue-excluding cells/well, and grown at a humidified $37^{\circ} \mathrm{C}, 5 \% \mathrm{CO}_{2}$ environment. The plating medium consisted of glutamine-free minimum essential medium (MEM; GIBCO, Scotland) supplemented with $10 \%$ fetal bovine serum (GIBCO), 10\% heat-inactivated equine serum (GIBCO), $25 \mathrm{~mm}$ glucose, $2 \mathrm{~mm}$ glutamine, and antibiotics as above. When non-neuronal cells reached confluency (after $3-5 \mathrm{~d}$ in culture), their proliferation was halted by exposure to $10 \mu \mathrm{M}$ cytosine-D-arabinoside (Sigma, UK). After $3 \mathrm{~d}$ of incubation, the cytosine-D-arabinoside was replaced with plating medium lacking fetal bovine serum. Subsequent medium replacements were carried out twice weekly. Only mature cultures $(13-17 \mathrm{~d}$ in vitro) were used for study.

Drug exposure. On the day of experiments, cells were washed with a control salt solution (CSS) composed of (mM) $\mathrm{NaCl}, 120$; Tris- $\mathrm{HCl}$, 25; glucose, 15; HEPES, $5 ; \mathrm{KCl}, 5.4 ; \mathrm{CaCl}_{2}, 1.8 ; \mathrm{MgCl}_{2}, 0.8(\mathrm{pH} \mathrm{7.4}$, $37^{\circ} \mathrm{C}$ ). Excitatory amino acids (EAAs) were dissolved in CSS and applied to cultures for 10-30 min on a hot plate, after which they were washed off with CSS; serum-free MFM was added and they were left to recover for $24 \mathrm{hr}$ in incubator. In separate experiments, medium was replaced with fresh culture medium containing IL-1 $\beta$, NGF, and/or a monoclonal NGF antiserum for $14 \mathrm{~d}$, depending on the experimental paradigm, before they were exposed to EAAs as described above. Thereafter, EAAs were washed off and serum-free MEM containing IL$1 \beta, N G F$, and/or a monoclonal NGF antiserum was added and cells were allowed to recover for a further $24 \mathrm{hr}$. For long-term exposure (up to $72 \mathrm{hr}$ ), compounds were dissolved in MEM lacking sera (see above) and experiments performed in the incubator. Preliminary experiments revealed that cultures tolerated serum-free MEM for up to $4 \mathrm{~d}$ (data not shown). Extent of cell damage was determined by measuring lactate dehydrogenase (LDH) release into the culture medium and by immunocytochemistry (see below).

Assessment of neurotoxicity. Neurotoxicity was quantified by spectrophotometric measurement of LDH efflux to the culture medium. This was routinely measured in triplicate using the "end-point" procedure previously described by Cabaud and Wroblinsky (1958). Samples of media $(0.5-1.0 \mathrm{ml})$ were added to $0.75 \mu \mathrm{M}$ sodium pyruvate $(\mathrm{pH} 7.5)$ containing $1.28 \mu \mathrm{mol}$ of $\beta$-nicotinamide adenine dinucleotide and incubated for $30 \mathrm{~min}$ at $37^{\circ} \mathrm{C}$. Subscquently, $200 \mu \mathrm{g} / \mathrm{ml}$ dinitrophenylhydrazine in $1 N$ hydrochloric acid was added and incubated for a further $20 \mathrm{~min}$ at room temperature. Thereafter, $0.4 \mathrm{~N}$ sodium hydroxide was added. The absorbance of the reaction mixture was measured spectrophotometrically at $445 \mathrm{~nm}$ and is inversely proportional to the amount of LDH present in the culture medium. Accuracy of the procedure was verified by assaying of standard LDH enzyme solutions. Concentrations of LDH measured in culture medium of experimental wells were converted into percentages of neurotoxicity by reading them off a standard curve of amount of LDH released against number of surviving neurons. This standard curve was constructed previously by exposing cultures to $300 \mu \mathrm{M}$ NMDA for up to $24 \mathrm{hr}$ and relating numbers of surviving neurons at various time points with amounts of LDH measured in the culture medium at those time points. This concentration of NMDA destroys selectively all ncurons present when applicd for $24 \mathrm{hr}$, without causing glial damage (Weiss et al., 1993).

Immunocytochemistry. For immunocytochemical analysis, cells were treated as above and fixed for 30 min with $75 \%$ ice-cold methanol at $4^{\circ} \mathrm{C}$. Cells were washed three times with Tris-buffered saline containing $0.5 \%$ Triton $\mathrm{X}-100$ (TBS-T), and incubated with $0.5 \% \mathrm{H}_{2} \mathrm{O}_{2}$ in TBS-T for $30 \mathrm{~min}$ at room temperature. Subsequently, cells were incubated for $16 \mathrm{hr}$ at room temperature with rabbit anti-cow glial fibrillary acidic protein (GFAP; DAKO) to detect astroglia, rat anti-Mac-1 antigen/CD11b (Mac-1; Boehringer Mannheim) to detect microglia, or mouse anti-human neuron-specific enolase (NSE; Serotec) to detect neurons. Cells were washed three times with TBS-T and incubated with a horseradish peroxidase-conjugated biotin-avidin complex for $30 \mathrm{~min}$ at room temperature. Thereafter, coloric product was developed by applying a solution of $0.05 \%$ diaminobenzidine tetrahydrochloride $/ 0.01 \%$ $\mathrm{H}_{2} \mathrm{O}_{2}$. Cells were dehydrated and mounted with Glycergel (DAKO). To assess nonspecific binding for each antiserum, adjacent wells were incubated simultaneously but primary antiserum omitted. Positive immunoreactivity was determined by comparing staining in the presence and absence of primary antiserum.

Quantification of specific cell types. Following immunocytochemistry, cells were identified according to their specific staining and counted manually in four randomly selected fields per well in three identically treated wells. Results are expressed as a percentage of control values.

Drugs. $N$-methyl-D-aspartate (NMDA), kainate, and $\alpha$-amino-3-hydroxy-5-methyl-4-isoxazolepropionic acid (AMPA) were from Tocris Neuramin (UK); glutamate, from Sigma (UK); human recombinant interleukin-1 $\beta$ (hrlL-1 $\beta$ ), from Glaxo Institute for Molecular Biology (Switzerland; specific activity, $3 \times 10^{7} \mathrm{U} / \mathrm{mg}$ protein; endotoxin contamination, $<0.3 \mathrm{EU} / \mathrm{mg}$ as assessed by Limulus amebocyte lysate assay); interleukin-1 receptor antagonist (IL-1 ra), from Synergen (USA); $\beta$-nerve growth factor (NGF), from Sigma (UK); mouse monoclonal antibody to nerve growth factor, from Boehringer Mannheim (UK)

Statistical analysis. Data are expressed as mean \pm SEM. Statistical analysis was performed using analysis of variance (ANOVA) followed by Scheffe's post hoc test with a significance level of probability less than $5 \%$.

\section{Results}

Primary cortical cells isolated from embryonic rats (day 18 of gestation) were cultured and maintained for 13-17 d to allow an extensive network of neuronal processes to form. In preliminary experiments, full concentration-response curves for effects of glutamate, NMDA, kainate, and AMPA on neuronal viability were established, the characteristics of which were fully compatible with those reported previously (Choi et al., 1987; Frandsen and Schousboe, 1987). Brief, 15 min exposure of mature cortical cultures to submaximal concentrations of glutamate (500 $\mu \mathrm{M})$, NMDA $(500 \mu \mathrm{M})$, kainate $(750 \mu \mathrm{M})$, or AMPA $(500 \mu \mathrm{M})$ resulted in neuronal damage (see Fig. 1) as assessed immunocytochemically and by the measurement of lactate dehydrogenase (LDH) efflux to the culture medium. These concentrations were used in all subsequent experiments. The absolute percent- 
Table 1. Effects of IL-1ß on EAA-induced neuronal death

\begin{tabular}{lll} 
& \multicolumn{2}{l}{ Neuronal number $(\%)$} \\
\cline { 2 - 3 } Treatment & Vehicle & IL-1 \\
\hline Control & $100 \pm 6$ & $106 \pm 11$ \\
Glutamate & $43 \pm 12^{* *}$ & $82 \pm 9 \dagger$ \\
NMDA & $31 \pm 5^{* *}$ & $79 \pm 12 \dagger$ \\
Kainate & $35 \pm 8^{* *}$ & $74 \pm 10 \ddagger$ \\
AMPA & $29 \pm 11^{* *}$ & $83 \pm 15 \ddagger$ \\
\hline
\end{tabular}

Data are the means \pm SEM $(n=3-5)$. Each point represents approximately 200-450 neurons counted in triplicate. Data are expressed as a percentage of the total number of neurons observed in untreated sister cultures, and were assessed by immunocytochemistry for neuron-specific enolase (NSE) as described in Materials and Methods. Significance was calculated using ANOVA followed by Scheffe's post hoc test. ${ }^{* *}, p<0.01$ versus neuronal number in vehicle-treated sister cultures; $\dagger, p<0.05$, and $\neq, p<0.01$, versus EAAinduced toxicity observed in vehicle-treated sister cultures.

ages of neurotoxicity caused by the concentrations of EAA used in the present studies are presented in Table 1.

\section{Effects of hrIL-1 $\beta$ on EAA-induced neuronal degeneration}

Exposure of cells to hrlL-1 $\beta$ for $24 \mathrm{hr}$ before, and $24 \mathrm{hr}$ after, exposure of mature cultures to submaximal concentrations of either glutamate, NMDA, kainate, or AMPA significantly attenuated neuronal death in a dose-dependent manner as assessed by measurement of the efflux of LDH to the culture medium (Fig. 1). Preliminary experiments demonstrated that significant inhibition of the cytotoxic effects of all the excitatory amino acids (EAAs) was observed at concentrations of 1000,500 , and $0.5 \mathrm{ng} / \mathrm{ml}(13,000,6500$ and $6.5 \mathrm{U} / \mathrm{ml}$, respectively) hrlL-1 $\beta$. The two highest doses of hrIL-1 $\beta$ tested offered a comparable degree of excitoprotection of approximately $40 \%$, while the lowest dose tested offered a somewhat lower and less reproducible degree of protection of approximately $10-20 \%$. Therefore, a concentration of $500 \mathrm{ng} / \mathrm{ml} \mathrm{hrlL-1 \beta}$ was used in all subsequent studies. Additional preliminary experiments indicated that preincubation with hrIL-1 $\beta$ for $24 \mathrm{hr}$ prior to exposure to EAAs was required for neuroprotective effects; only a small, nonsignificant attcnuation of the EAA-induced cytotoxicity by hrIL-1 $\beta$ was observed when hrIL-1 $\beta$ was applied simultaneously with the EAAs (data not shown).

To assess whether hrlL-I $\beta$ specifically protects neurons against EAA toxicity, neurons were identified using immunocytochemistry for neuron-specific enolase (NSE) and cell counts performed manually. A pattern identical to that of changes in LDH release was observed. Exposure to glutamate, NMDA, kainate, or AMPA significantly reduced neuronal numbers (Table 1). Exposure to hrIL-1 $\beta$ for $24 \mathrm{hr}$ before, and $24 \mathrm{hr}$ after, treatment of cultures with EAAs resulted in an increased neuronal number, compared to control wells in which hrlL-1 $\beta$ was omitted. This effect appeared to be accompanied by a modest microgliosis and astrogliosis as indicated by an increase in immunoreactivity for Mac-I and GFAP (data not shown).

\section{Effects of $I L-1$ receptor antagonist on hrIL-1 $\beta$-induced neuroprotection}

To determine the specificity of the neuroprotective actions of hrIL-1 $\beta$, the effects of an IL-1 receptor antagonist (IL-1 ra) on $\mathrm{LDH}$ release in response to EAAs were investigated. Simultaneous exposure of cultures to IL-1 ra $(50 \mu \mathrm{g} / \mathrm{ml})$ and $\mathrm{hrIL}-1 \beta$ (500 ng/ml) for $24 \mathrm{hr}$ before, and for $24 \mathrm{hr}$ after, exposure to
EAA

$E A A+I L-1 \beta(500 n g / m l)$

$E A A+I L-1 \beta+I L-1 r a(50 \mu \mathrm{g} / \mathrm{mI})$

$E A A+I L-1 r a(50 \mu g / m)$

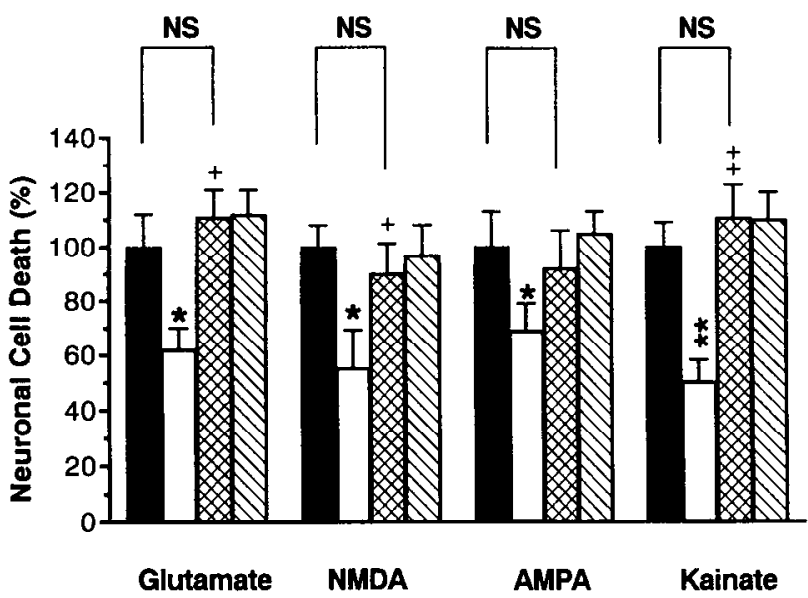

Figure 1. Neuronal cell death induced by either glutamate $(500 \mu \mathrm{M})$, NMDA $(500 \mu \mathrm{M})$, AMPA $(500 \mu \mathrm{M})$, or kainate $(750 \mu \mathrm{M})$ and modification of the degree of neurotoxicity by IL-1 $\beta$ and IL-1 ra. Cultures were exposed to EAAs for $15 \mathrm{~min}$ and neuronal death was assessed by measuring efflux of LDH to culture medium $24 \mathrm{hr}$ later (solid bars). Sister cultures were exposed to IL-1 $\beta$ (open bars), IL-1 ra (hatched bars), or a combination of IL-1 $\beta$ and IL-1 ra (crosshatched bars) for $24 \mathrm{hr}$ before and $24 \mathrm{hr}$ following application of EAAs, after which the degree of neurotoxicity was measured as above. Data are mean $\pm \mathrm{SEM}, n=4-$ 6. Significance was calculated using ANOVA followed by Scheffe's post hoc test. ${ }^{*}, p<0.05$, and $* *, p<0.01$, versus neuronal number in sister cultures exposed to EAAs (solid bars).,$+ p<0.05$, and ++ , $p<0.01$, versus neuronal number in sister cultures exposed to EAAs in the presence of IL-1 $\beta$ (open bars). No statistical significance was observed between the degree of neurotoxicity induced by any of the EAAs (solid bars) and that seen in cultures exposed to EAAs in the presence of a combination of IL-1 $\beta$ and IL-1ra (crosshatched bars).

submaximal concentrations of EAAs significantly reversed the neuroprotective effects of hrlL-1 $\beta$ on EAA-induced neurodegeneration (Fig. 1). Thus, no significant differences were observed between the levels of neurotoxicity found in cultures exposed to FAAs and those exposed to EAAs in the presence of both IL-1 ra and hrIL-1 $\beta$ (Fig. 1). Application of IL- 1 ra, in the absence of hrlL-1 $\beta$, for $24 \mathrm{hr}$ before and for $24 \mathrm{hr}$ following exposure to EAAs had no effect on the extent of neurotoxicity (Fig. 1).

Immunocytochemical analysis for NSE revealed that IL-1 ra reversed the neuroprotective effects of hrIL-1 $\beta$ on EAA-induced neurotoxicity (data not shown).

\section{Effects of a neutralizing NGF antiserum}

Cultures were grown in medium containing $50 \mathrm{ng} / \mathrm{ml} \mathrm{NGF}$ antiserum for $4 \mathrm{~d}$ prior to experimentation. In control experiments, NGF antiserum treatment had little effect on neuronal cell number (data not shown). NGF antiserum antagonized the neuroprotective actions of hrIL- $1 \beta$ against E $\Lambda \Lambda$ induced neurodegeneration as assessed by measurement of $\mathrm{LDH}$ release into the culture medium (Fig. 2). Thus, the degree of excitotoxicity after NGF antiserum treatment in IL-1 $\beta$-pretreated wells was comparable to that observed in the wells treated with the EAA alone (Fig. 2).

A similar pattern of responses was observed when neuronal 
EAA

$E A A+I L-1 \beta(500 \mathrm{ng} / \mathrm{ml})+\mathrm{NIS}$

EAA + IL-1 $\beta+$ anti-NGF $(50 \mathrm{ng} / \mathrm{ml})$

EAA + anti-NGF (50ng/ml)

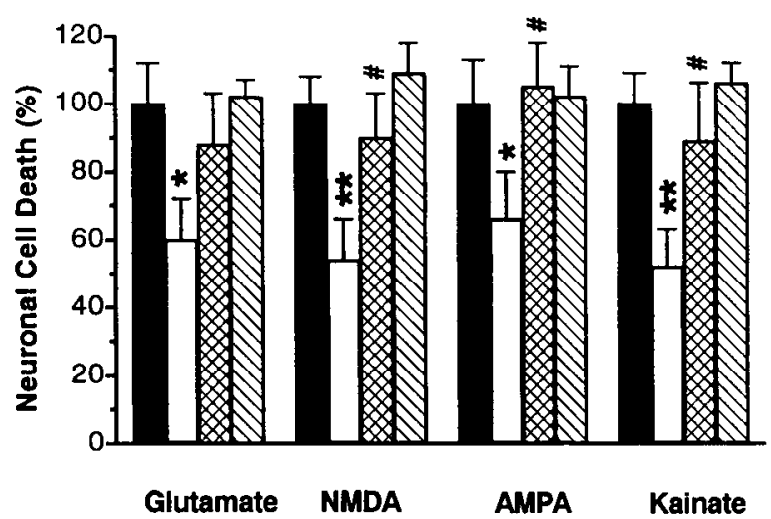

Figure 2. Neuronal cell death induced by either glutamate $(500 \mu \mathrm{M})$, NMDA $(500 \mu \mathrm{M})$, AMPA $(500 \mu \mathrm{M})$, or kainate $(750 \mu \mathrm{M})$ and modification of the degree of neurotoxicity by IL- $1 \beta$ and a neutralizing antiserum to NGF (anti-NGF) or nonimmune serum (NIS). Cultures were exposed to EAAs for $15 \mathrm{~min}$ and neuronal death was assessed by measuring efflux of LDH to culture medium $24 \mathrm{hr}$ later (solid bars). Sister cultures were preexposed to IL-1 $\beta$ ( $24 \mathrm{hr}$; open bars), NGF antiserum (hatched bars), or a combination of IL-1 $\beta$ ( $24 \mathrm{hr}$ ) and neutralizing NGF antiserum ( $4 \mathrm{~d}$; crosshatched bars) before and $24 \mathrm{hr}$ following application of EAAs, after which the degree of neurotoxicity was measured as above. Data are mean $\pm \mathrm{SEM}, n=4-6$. Significance was calculated using ANOVA followed by Scheffe's post hoc test. ${ }^{*}, p<0.05$, and $* *, p<0.01$, versus neuronal number in sister cultures exposed to EAAs (solid bars). \#, $p<0.05$ versus neuronal number in sister cultures exposed to EAAs plus IL-1 $\beta$ (open bars).

number was assessed immunocytochemically with an antiserum to NSE: NGF antiserum prevented the loss of neuronal number following exposure to EAAs. Control experiments consisting of preincubation with mouse nonimmune serum did not modify the protective effects of hrIL-1 $\beta$ on EAA-induced neurodegeneration (data not shown).

\section{Effects of exogenous $N G F$}

To study the effects of exogenous NGF on neuronal viability following exposure to EAAs, 50-100 ng mouse NGF (Sigma) was added to culture medium for $48 \mathrm{hr}$ before, during, and for $24 \mathrm{hr}$ following exposure to EAAs (Fig. 3). NGF caused concentration-dependent inhibition of excitotoxicity, with maximal inhibition observed with a concentration of $100 \mathrm{ng} / \mathrm{ml} \mathrm{NGF}$ (as assessed by measurement of LDH release). At a concentration of $50 \mathrm{ng} / \mathrm{ml}$, NGF offered little neuroprotection against EAA neurotoxicity.

When cultures were pretreated for $24 \mathrm{hr}$ with a combination of $500 \mathrm{ng} / \mathrm{ml} \mathrm{hrIL-1 \beta}$ and $100 \mathrm{ng} / \mathrm{ml} \mathrm{NGF}$, a high degree of neuroprotection against glutamate, NMDA, AMPA, and kainate toxicity was observed (Fig. 3).

\section{Effects of long-term exposure to high concentrations of hrIL-I $\beta$}

Exposure of cultures to high concentrations of hrIL-1 $\beta$ (10-100 $\mu \mathrm{g} / \mathrm{ml}$ ) for up to $72 \mathrm{hr}$ caused a reduction in neuronal number in a time- and dose-dependent manner as assessed by measurement of LDH release (Figs. 4, 5). Significant cell death was

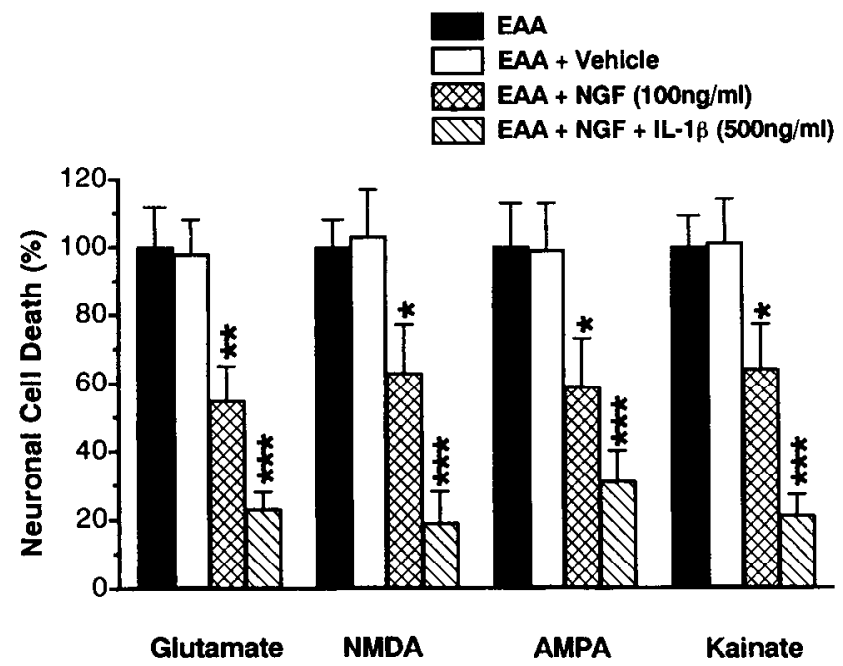

Figure 3. Neuronal cell death induced by either glutamate $(500 \mu \mathrm{M})$, NMDA $(500 \mu \mathrm{M})$, AMPA $(500 \mu \mathrm{M})$, or kainate $(750 \mu \mathrm{M})$ and modification of the degree of neurotoxicity by NGF. Cultures were exposed to EAAs for $15 \mathrm{~min}$ and neuronal death was assessed by measuring efflux of LDH to culture medium 24 hr later (solid bars). Sister cultures were exposed to NGF (crosshatched bars) or a combination of NGF and IL-1 $\beta$ (hatched bars) for $48 \mathrm{hr}$ before and $24 \mathrm{hr}$ following application of EAAs, after which the degree of neurotoxicity was measured as above. Data are mean $\pm \mathrm{SEM}, n=3-6$. Significance was calculated using ANOVA followed by Scheffe's post hoc test. *, $p<0.05 ; * *, p$ $<0.01$; and $* * *, p<0.001$; versus neuronal number in sister cultures exposed to EAAs (solid bars).

observed following an exposure time of $72 \mathrm{hr}$, at a concentration of $100 \mu \mathrm{g} / \mathrm{ml}$ hrIL- $1 \beta$.

Immunocytochemistry for NSE demonstrated that this increase in $\mathrm{LDH}$ release $(63 \%)$ caused by long-term exposure to

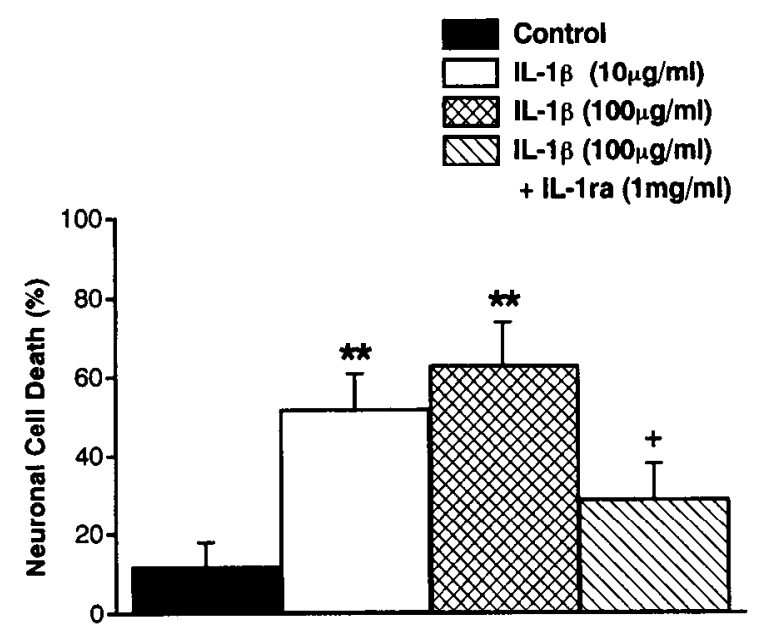

Figure 4. Neuronal cell death induced by long-term exposure to various concentrations of IL-1 $\beta$ and modification of the degree of neurotoxicity by IL-1 ra. Cultures were exposed to the indicated concentrations of IL-1 $\beta$ for $72 \mathrm{hr}$ before neuronal death was assessed by measuring efflux of LDH to culture medium (crosshatched and open bars). Sister cultures were exposed to a combination of both IL-1 ra and IL-1 $\beta$ for $72 \mathrm{hr}$ (hatched bar), after which the degree of neurotoxicity was measured as above. Data are mean \pm SEM, $n=3-6$. Significance was calculated using ANOVA followed by Scheffe's post hoc test. + , $p<0.05$ versus neuronal number in cultures exposed to $100 \mu \mathrm{g} / \mathrm{ml} \mathrm{IL-}$ $1 \beta$ for $72 \mathrm{hr}$ (crosshatched bar). ${ }^{*}, p<0.01$ versus neuronal numbers in vehicle-treated control sister cultures (solid bar). 


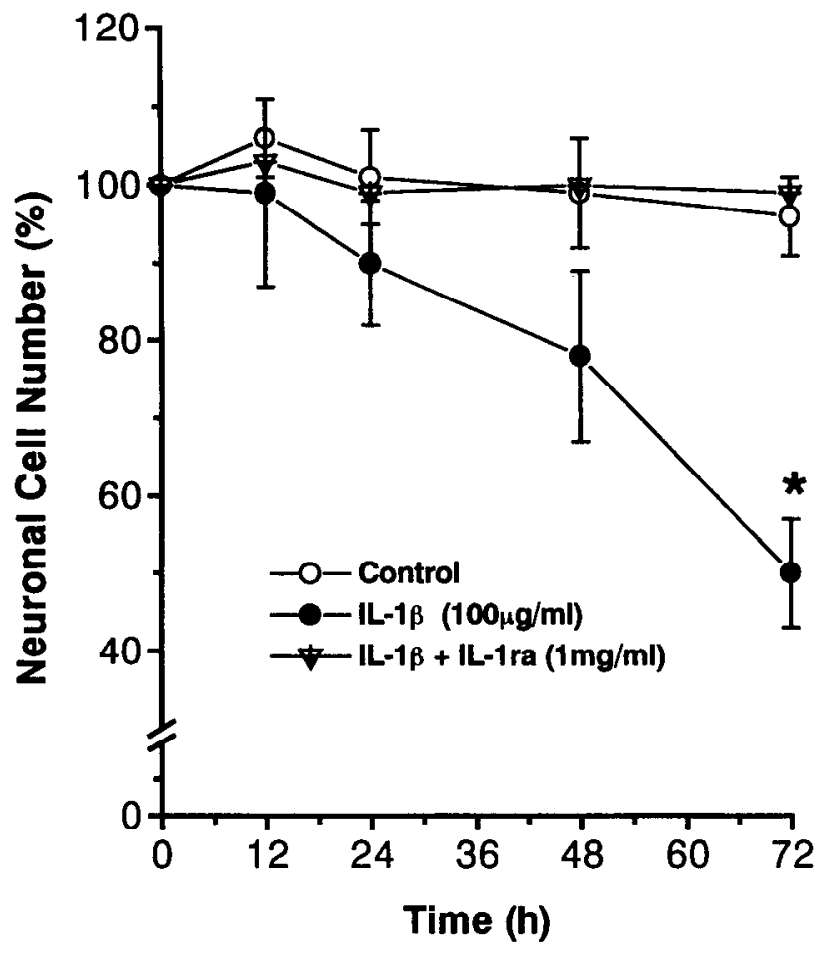

Figure 5. Time course of neuronal cell death induced by long-term exposure to IL- $1 \beta$ and modification of the degree of neurotoxicity by IL-1 ra. Cultures were exposed to the indicated concentration of IL-1 $\beta$ up to $72 \mathrm{hr}$ before neuronal death was assessed (closed circles). Sister cultures were exposed to a combination of both IL-1ra and IL-1 $\beta$ up to $72 \mathrm{hr}$ (open triangles), after which the degree of neurotoxicity was measured as above. Data are the means $\pm \mathrm{SEM}, n-35$. Each point represents approximately $200-450$ neurons counted in triplicate. Data are expressed as a percentage of the total number of neurons observed in untreated sister cultures, and were assessed by immunocytochemistry for neuron-specific enolase (NSE) as described in Materials and Methods. Significance was calculated using ANOVA followed by Scheffe's post hoc test. ${ }^{*}, p<0.05$ versus neuronal number in cultures exposed for $72 \mathrm{hr}$ to vehicle (open circles) or a combination of IL-1 $\beta$ and IL1 ra (open triangles).

hrIL- $1 \beta$ was accompanied by a significant reduction in the number of NSE-positive cells, indicating specific neurotoxic effects of hrIL-1 $\beta$ (Fig. 5). In addition, exposure of cultures to 100 $\mu \mathrm{g} / \mathrm{ml}$ hrIL- $1 \beta$ for $72 \mathrm{hr}$ resulted in a large increase in GFAP and Mac-1 immunoreactivity, indicating potent astrogliotic and microgliotic properties of hrIL-1 $\beta$ (data not shown). The specificity of the neurotoxic effects of $100 \mu \mathrm{g} / \mathrm{ml} \mathrm{hrIL-1 \beta}$ was demonstrated by the coapplication of $1 \mathrm{mg} / \mathrm{ml}$ IL- 1 ra (Figs. 4,5 ). It was observed that IL-1 ra prevented IL-1 $\beta$ neurotoxicity.

\section{Discussion}

The results of the present study indicate that interleukin-1 $\beta$ (IL$1 \beta$ ) can act via, and in cooperation with, NGF to modify the neurotoxic actions of excitatory amino acids (EAAs). The effects of hrIL-1 $\beta$ and NGF on EAA actions appear to be "nonselective," in that the neurotoxic effects of EAAs acting on either NMDA or non-NMDA receptor subtypes were similarly affected by hrIL-1 $\beta$ and NGF.

It has recently been reported that several interleukins, including IL-1, -4, -6, -7, and -8 , can support neuronal viability in vitro, since they potently induce neurite branching and extension and increase neuronal survival (Hama et al., 1989; Fagan and Gage, 1990; Araujo, 1992; Araujo and Cotman, 1993). The latter studies describe the neurotrophic effects of IL-1 at concentrations of $10 \mathrm{ng} / \mathrm{ml}$. Because biological activity of the IL-1 used was not provided in these studies, direct comparison with the trophic effects reported here cannot be made. In the present study, protection against EAA-induced neurodegeneration was observed at $6500 \mathrm{U} / \mathrm{ml}(500 \mathrm{ng} / \mathrm{ml})$, although 13,000 and 6.5 $\mathrm{U} / \mathrm{ml}$ also provided a significant degree of excitoprotection. It is possible that neuroprotective effects can be observed at lower concentrations. It appeared that the neuroprotective actions of IL-1 were accompanied by an increase in glial cell number, although this was not quantified. Nevertheless, the ability of IL-1 to stimulate glial activation and proliferation has been demonstrated previously (Giulian and Lachman, 1985), and suggests that neuroprotective effects of IL-1 may be mediated by glial production of growth factors. This is supported by our finding that inhibition of protein synthesis by $10 \mu \mathrm{M}$ cycloheximide significantly reversed the degree of excitoprotection offered by IL$1 \beta$ (data not shown). The above suggestion does not exclude any direct neuronal effects of IL-1, as has been described for several other cytokines/growth factors such as ciliary neurotrophic factor (CNTF) and fibroblast growth factor (FGF) (Walicke and Baird, 1988; Unsicker et al., 1992). However, the monoclonal antibody to NGF used in the present studies does not appear to interfere with either the biological activity of IL-1 in D10N thymocyte proliferation assay (Hopkins and Humphreys, 1989; S. Hopkins, unpublished observations) or crossreact with FGF, IGF, or CNTF (Boehringer Mannheim, personal communication), suggesting that the excitoprotective effects of IL-1 observed in this study may be mediated largely by NGF. However, we cannot completely rule out the involvement of growth factors other than the above in the neuroprotective effects of IL- $1 \beta$.

A role for endogenous IL- 1 in the control of neuronal survival in vitro has recently been demonstrated by Brenneman et al. (1992). They observed that administration of an antiserum to IL$1 \alpha$ to cultured spinal cord neurons caused increased neuronal death, an effect that was reversed by addition of IL- $1 \alpha$ (Brenneman et al., 1992). The authors speculated that one of the mechanisms by which IL- 1 is neuroprotective may be via the induction of NGF in astroglia. Indeed, the ability of IL-1 to induce NGF mRNA and protein in astroglia has previously been reported (Carman-Krazan et al., 1991). This suggestion is further supported by the recent finding that astrocyte-conditioned medium enhances septal cholinergic neuronal choline acetyltransferase activity, an effect that appears to be upregulated by IL$1 \beta$ and mediated by NGF from astrocytic origin (Yoshida et al., 1992). Thus, activation and proliferation of astro- or microglia by IL-1 could result in the release of NGF and may subsequently confer neuroprotection. This hypothesis has been suggested previously but was based on circumstantial evidence. To our knowledge, the present study provides the first direct evidence that IL-1 can modify neurotoxicity through an interaction with NGF and that exogenous NGF directly inhibits excitotoxic damage.

It has been reported previously that exogenous NGF can protect cultured cortical neurons against hypoglycemia and some excitotoxic insults (Cheng and Mattson, 1991; Shimohama et al., 1993). Our data agree with these studies and extend them by the demonstration that both exogenous and endogenous NGF can protect neurons against both NMDA and non-NMDA receptormediated neurotoxicity. Previous studies have been unable to show neuroprotective effects of exogenous NGF against excitotoxicity in vitro. Mattson et al. (1989) demonstrated that NGF 
failed to rescue 5-d-old hippocampal neurons in culture exposed to glutamate. In addition to obvious differences in culture conditions and neuronal cell types, these workers used lower concentrations of NGF (10 ng/ml NGF) than those employed in the present study and that of Shimohama et al. (1993; $100 \mathrm{ng} / \mathrm{ml})$. Furthermore, their cultures were very young $(5 \mathrm{~d})$ compared to 14-17 d in this study. This may be crucial, since it has previously been reported that NGF receptor expression is under developmental control (von Bartheld et al., 1991; von Bartheld and Bothwell, 1992). Thus, total NGF receptor number and/or NGF receptor binding characteristics may depend on the age of the culture. Finally, cortical neurons may be more sensitive to the trophic actions of NGF than hippocampal neurons.

From the present study it is not clear how NGF exerts its neuroprotective effects. Some data suggest that NGF may exert its neuroprotective actions by reducing accumulation of intracellular calcium through the induction of calbindin-D28k (Iacopino et al., 1992), thus preventing calcium-dependent neuronal degeneration. However, other workers have been unable to observe an effect of NGF on calbindin-D28k expression, and this therefore remains controversial (Collazo et al., 1992; Cheng et al., 1994). Furthermore, it has been demonstrated that the effects of NGF are mediated partly by a high-affinity tyrosine kinase A $\mathrm{NGF}$ receptor (TrkA) and the low-affinity NGF receptor $\mathrm{p} 75^{\mathrm{NGFR}}$ (Hempstead et al., 1991; Klein et al., 1991). Recent data indicate that $\mathrm{p} 75^{\mathrm{NGFR}}$ increases the affinity of TrkA for NGF and enhances its specificity for other members of the NGF family (Ip et al., 1993). p75 ${ }^{\mathrm{NGFR}}$ has been shown to act as a constitutive neurotoxicity-promoting receptor since its expression, when unoccupied, induces neuronal death through apoptosis (Rabizadeh et al., 1993). EAA treatment may cause neuronal death through upregulation of this low-affinity NGF receptor. In contrast, binding of NGF to $p 75^{\mathrm{NGFR}}$ has been demonstrated to confer neuroprotection (Rabizadeh et al., 1993), suggesting that the neuroprotective actions of NGF against EAA toxicity may involve p $75^{\mathrm{NGFR}}$. Activation of both NMDA and non-NMDA receptors has been demonstrated to induce NGF mRNA in vivo and in vitro (Zafra et al., 1990; Ballarin et al., 1991), yet agonists of these EAA receptors are potent neurotoxins. A possible explanation for this apparent paradox may be that NGF induced following NMDA and non-NMDA receptor activation preferentially binds to the high affinity TrkA NGF receptor, leaving the low-affinity NGF receptor $\mathrm{p} 75^{\mathrm{NGFR}}$ unoccupied. This would allow $\mathrm{p} 75^{\mathrm{NGFR}}$ to exert its neurodegenerative effects, antagonizing/reversing any beneficial actions of NGF on the high-affinity NGF receptor. However, since recent data indicate that glutamate-induced neuronal death may not involve apoptosis (Dessi et al., 1993), this mechanism remains speculative. Finally, when neurons were exposed to a combination of IL-1 $\beta$ and NGF, a large additive neuroprotective effect was observed. This suggests that the concentration of $\mathrm{II}-1 \beta$ used in this study was insufficient to induce NGF in those quantities required to obtain maximal neuroprotection.

An additional finding of the present study is that high concentrations of IL-1 $\beta$ is toxic to cortical neurons. These effects are observed only following long-term exposures ( $72 \mathrm{hr}$ ) to high concentrations of IL- $1 \beta\left(100 \mu \mathrm{g} / \mathrm{ml}, 1.3 \times 10^{\circ} \mathrm{U} / \mathrm{ml}\right)$. This finding is in agreement with earlier reports that interleukins can act as neurotoxins at high concentrations (Araujo and Cotman, 1991; Araujo, 1992). These workers investigated the neurotoxic effects of IL- 1 at doses up to $1 \mu \mathrm{g} / \mathrm{ml}$ (biological activity unknown) on cultured hippocampal neurons. While the dose of
IL-1 used in our study is 100 -fold greater, essentially identical results were obtained. At present, the mechanism of IL- $1 \beta$ neurotoxicity is unknown, but appears to be mediated by the type 1 IL-1 receptor since application of IL-1 ra reduced its neurotoxicity. Nevertheless, the in vitro toxicity of IL-1 is in concordance with the proposed role of IL-1 in neurodegeneration in vivo (Rothwell and Relton, 1993). Administration of IL-1 into the brain of experimental animals elicits processes characteristic of brain trauma, including glial activation and proliferation, neuronal sprouting, scar formation, and neovascularization (Giulian and Lachman, 1985; Woodward et al., 1989). While constitutive expression of IL-1 protein and its mRNA is low in normal brain, various CNS disorders in humans and experimental animals, including cerebral ischemia, result in increased expression of II -1 (Giulian and Lachman, 1985; Minami et al., 1991, 1993). Furthermore, increased concentrations of IL- 1 have been reported in the brain or cerebrospinal fluid of patients suffering from neurodegenerative diseases such Alzheimer's disease and HIV (Gallo et al., 1989; Griffin et al., 1989).

Using an interleukin-1 receptor antagonist (IL-1 ra), we recently highlighted the importance of endogenous IL-1 in neurodegeneration (Relton and Rothwell, 1992). It was found that neuronal death caused by focal cerebral ischemia or glutamatergic lesions of the corpus striatum in the rat was markedly inhibited by IL-1 ra, suggesting that endogenous IL-1 can mediate neuronal death. This is further supported by our recent finding that IL-1 ra also protects the rat striatum against nonNMDA receptor-mediated neurodegeneration (C. Lawrence, P. J. L. M. Strijbos, and N. J. Rothwell, unpublished observations). Thus, it appears that the neurotoxic actions of IL-1 in vitro are comparable with those in vivo, although the mechanisms by which IL-1 is neurotoxic in these two experimental systems may be distinct. It is currently unknown whether IL-1, when injected at low concentrations, offers protection against FAA-induced neurotoxicity in vivo. However, considering that administration of IL-1 into the brain of experimental animals induces NGF (Lindholm et al., 1987; Friedman et al., 1990) and that NGF protects against excitotoxicity in vivo (Frim et al., 1993), this proposal seems reasonable.

Nevertheless, it appears that IL-1 is able to exert dual roles. Under conditions where large quantities of IL-1 are produced such as cerebral ischemia, IL-1 may be detrimental to neurons. In contrast, in situations where relatively small amounts of IL-1 are produced (e.g., in normal brain), IL-1 may maintain neuronal viability by acting as a neurotrophic factor. Therefore, it seems important that IL-1 production in the CNS is controlled with great precision, and that any disturbance in these processes may result in changes in neuronal viability. It is currently not clear why increased expression of IL-1 results in neurotoxicity in vivo and in vitro, since this should confer increased production of NGF.

In summary, the present study provides support for the hypothesis that cytokines, growth factors, and excitatory neurotransmitters can interact to influence neuronal viability. The potent neurotoxic actions of glutamate, NMDA, kainate, and AMPA to cultured cortical neurons can be inhibited by pretreatment with IL- $1 \beta$ or NGF. The finding that IL- $1 \beta$ reduced the extent of EAA-induced neuronal death through an action on nerve growth is novel and may be relevant to understanding and treatment of neurodegenerative diseases. 


\section{References}

Araujo D (1992) Contrasting effects of specific lymphokines on the survival of hippocampal neurons in culture. In: Treatment of dementias (Meyer E, ed), pp 113-122. New York: Plenum.

Araujo D, Cotman C (1991) Transient neurotrophic effects of interleukins on hippocampal neurons in vitro. Third IBRO World Conference on Neuroscience, 243.

Araujo D, Cotman C (1993) Trophic effects of interleukin-4,-7 and-8 on hippocampal neuronal cultures: potential involvement of glia-derived factors. Brain Res 600:49-55.

Brenneman D, Schultzberg M, Bartfai T, Gozes I (1992) Cytokine regulation of neuronal survival. J Neurochem 58:454-460.

Cabaud P, Wroblinsky F (1958) Colorimetric measurement of lactic dehydrogenase activity in body fluids. Am J Clin Pathol 30:234-239.

Carman-Krazan M, Vige X, Wise B (1991) Regulation by interleukin-1 of nerve growth factor secretion and nerve growth factor mRNA expression in rat prinary astroglial cultures. J Neurochem 56:636-643.

Cheng B, Mattson MP (1991) NGF and bFGF protect cultured rat hippocampal and human cortical neurons against hypoglycemic damage by stabilizing calcium homeostasis. Neuron 7:1031-1041.

Cheng B, Christakos S, Mattson MP (1994) Tumor necrosis factors protect neurons against metabolic-excitotoxic insults and promote maintenance of calcium homeostasis. Neuron 12:139-153.

Choi D, Maulucci-Gedde M, Kriegstein A (1987) Glutamate neurotoxicity in cortical cell culture. J Neurosci 7:357-368.

Choi D, Koh J, Peters S (1988) Pharmacology of glutamate neurotoxicity in cortical cell culture: attenuation by NMDA antagonists. J Neurosci 8:185-196.

Collazo D, Takahishi H, McKay RD (1992) Cellular targets and trophic functions of neurotrophin-3 in the developing rat hippocampus. Neuron 9:643-656.

Dessi F, Charriaut-Marlangue C, Khrestchatisky M, Ben Ari Y (1993) Glutamate-induced neuronal death is not programmed cell death in cerebellar culture. J Neurochem 60:1953-1955.

Fagan A, Gage F (1990) Cholinergic sprouting in the hippocampus, a proposed role for IL-1. Exp Neurol 110:105-120.

Frandsen A, Schousboe A (1987) Time and concentration dependency of the toxicity of excitatory amino acids on cerebral neurons in primary culture. Neurochem Int 10:583 591.

Friedman W, Larkfors L, Ayer-Lelievre C, Ebendal T, Olsen L, Persson $\mathrm{H}$ (1990) Regulation of $\beta$-nerve growth factor expression by inflamInatory mediators in hippocampal cultures. J Neurosci Res 27:374 382.

Frim D, Short P, Rosenberg W, Simpson J, Breakefield X, Isacson O (1993) Local protective effects of nerve growth factor-secreting fibroblasts against excitotoxic lesions in the rat striatum. J Neurosurg 78 : 267-273.

Gallo P, Frey K, Rordorf C, Lazdins J, Tavolato B, Fontana A (1989) Human immunodeficiency type 1 (HIV-1) infection of the central nervous system: an evaluation of cytokines in cerebrospinal fluid. J Neuroimmunol 23:109-116.

Giulian D, Lachman L (1985) Interleukin-1 stimulation of astroglial proliferation after brain injury. Science 228:497-

Gonzalez D, Les W, Hiney J, Ojeda S, Saneto R (1990) Expression of $\beta$ - nerve growth factor in cultured cells derived from the hypothalamus and cerebral cortex. Brain Res 511:249-258.

Griffin W, Stanley L, Ling C, White L, Macleod V, Perrot L, White C, Araoz C (1989) Brain interleukin-1 and S-100 immunoreactivity are elevated in Down syndrome and Alzheimer disease. Proc Natl Acad Sci USA 86:7611-7615.

Hama T, Miyamoto $M$, Tsukui $H$, Nishio $C$, Hatanaka $H$ (1989) Interleukin- 6 as a neurotrophic factor for promoting the survival of cultured basal forebrain cholinergic neurons from postnatal rats. Neurosci Lett 104:340-344

Hempstead B, Martin-Zanca D, Kaplan D, Parade D, Chao M (1991) High-affinity NGF binding requires co-expression of the trk proto-oncogene and the low-affinity NGF receptor. Nature 350:678-683.

Hopkins SJ, Humphreys M (1989) Simple, sensitive and specific bioassay of interleukin-1. J Immunol Methods 120:271-276.

Iacopino A, Christakos S, Modi P, Altar C (1992) Nerve growth factor increases calcium binding protein (calbindin-D28k) in rat olfactory bulb. Brain Res 578:305-310.

Ip N, Stitt T, Tapley P, Klein R, Glass D, Fandl J, Greene L, Barbacid $M$, Yancopoulos G (1993) Similarities and differences in the way neurotrophins interact with Trk receptors in neuronal and non-neuronal cells. Neuron 10:137-149.

Klein R, Jing S, Nanduri V, O'Rourke E, Barbacid M (1991) The trk proto-oncogene encode a receptor for nerve growth factor. Cell 65 : $189-197$.

Kromer L (1987) Nerve growth factor treatment after brain injury prevents neuronal death. Science 235:214-216.

Lindefors N, Ballarin M, Ernfors P, Falkenberg T, Perrson M (1992) Stimulation of glutamate receptors increases expression of brain derived neurotrophic factor mRNA in rat hippocampus. Ann NY Acad Sci 648:296-299.

Lindholm D. Heumann R. Meyer M, Thoenen H (1987) Interleukin-1 regulates synthesis of nerve growth factor in non-neuronal cells of rat sciatic nerve. Nature 330:658-659.

Mattson M, Murrain M, Guthrie P, Kater S (1989) Fibroblast growth factor and glutamate: opposing roles in the generation and degeneration of hippocampal neuroarchitecture. J Neurosci 9:3728-3740.

Minami M, Kuraishi Y, Satoh M (1991) Effects of kainic acid on messenger mRNA levels of IL-1 $\beta$, IL-6, TNF and LIF in the rat brain. Biochem Biophys Res Commun 176:593-598.

Minami M, Kuraishi Y, Yabuuchi K, Yamazaki A, Satoh M (1993) Induction of interleukin- $1 \beta$ in rat brain after transient forebrain ischemia. J Neurochem 58:390-392.

Patterson P, Nawa H (1993) Neuronal differentiation factors/cytokines and synaptic plasticity. Cell 72:123-137.

Rabizadeh S, Oh J, Zhong L, Yang J, Bitler C, Butcher L, Bredesen D (1993) Induction of apoptosis by the low affinity NGF receptor. Science 261:345-348.

Relton J, Rothwell N (1992) Interleukin receptor antagonist inhibits neuronal damage induced by cerebral ischaemia or NMDA-receptor activation in the rat. Brain Res Bull 585:135-141.

Rothwell N, Relton J (1993) Involvement of cytokines in acute neurodegeneration in the CNS. Neurosci Biobehav Rev 17:217-227.

Schumacher J, Short M, Hyman B, Breakefield X, Isacson O (1991) Intracerebral implantation of nerve growth factor-producing fibroblasts protects against neurotoxic levels of excitatory amino acids. Neuroscience 45:561-570.

Shigeno T, Mima T, Takakura K, Graham I, Kato G, Hashimoto Y, Furukawa S (1991) Amelioration of delayed neuronal death in the hippocampus by nerve growth factor. J Neurosci 11:2914-2919.

Shimohama S, Ogawa N, Tamura Y, Akaike A, Tsukahara T, Iwata $\mathrm{H}$, Kimura J (1993) Protective effect of nerve growth factor against glutamate-induced neurotoxicity in cultured cortical neurons. Brain Res 632:296-302.

Strijbos P, Wilde B, Rothwell N (1993) Neurotoxic and neuroprotective actions of interlcukin- $1 \beta$ on cortical ncurons in culture. Soc Neurosci Abstr 19:1891.

Unsicker K, Reichert-Preibsch H, Wewetzer K (1992) Stimulation of neuronal survival by basic FGF and CNTF is a direct effect and not mediated by non-neuronal cells: evidence from single cell cultures. Dev Brain Res 65:285-288.

Von Bartheld C, Bothwell M (1992) Development and distribution of noradrenergic neurons and their trophic phenotypes in the avian cereleus complex and midbrain tegmentum. J Comp Neurol 320:497-500.

Von Bartheld C, Patterson S, Heuer J, Wheeler E, Bothwell M (1991) Expression of nerve growth factor (NGF) receptors in the developing inner ear of chick and rat. Development 113:445-470.

Walicke P, Baird A (1988) Neurotrophic effects of basic and acidic fibroblast growth factors are not mediated through glial cells. Dev Brain Res 40:71-79.

Weiss JH, Hartley DM, Koh J, Choi D (1993) AMPA receptor activation potentiates zinc neurotoxicity. Neuron 10:43-49.

Yabuuchi K, Minlani M, Katsuntata S, Satoh M (1993) In situ hybridization study of interleukin-1 $\beta$ mRNA induced by kainic acid in the rat brain. Mol Brain Res 20:153-161.

Yoshida K, Gage F (1992) Cooperative regulation of nerve growth factor synthesis and secretion in fibroblasts and astrocytes by fibroblast growth factor and other cytokines. Brain Res 569:14-25.

Yoshida K, Kakihana M, Chen L, Ong M, Baird A, Gage F (1992) Cytokine regulation of nerve growth factor-mediated cholinergic neurotrophic activity synthesized by astrocytes and fibroblasts. J Neurochem 59:919-931.

Zafra F, Hengerer B, Leibrock J, Thoenen H, Lindholm D (1990) Activity dependent regulation of BDNF and NGF mRNAs in the rat hippocampus is mediated by non-NMDA glutamate receptors. EMBO J 9:3545-3550 